COMUNICAÇÕES ORAIS / COMUNICACIONES ORALES
10. Direito
Sanitário
Internacional/Derecho
Sanitario Internacional

\title{
10.01 \\ O direito à saúde e a participação comunitária em saúde nos documentos internacionais: anotações preliminares
}

The right to health and community participation in health in international documents: preliminary notes

\section{Reginaldo de Souza Vieira}

Doutor em Direito. Líder do Laboratório de Direito Sanitário e Saúde Coletiva e Professor de Programa de Pós-Graduação em Desenvolvimento Socioeconômico da Universidade do Extremo Sul Catarinense (UNESC). Criciúma, SC, Brasil.

Resumo: A Declaração Universal dos Direitos Humanos não dissocia a saúde dos outros condicionantes necessários para que se possa ter uma vida digna. Isto é, não se pode avaliar a existência ou não de uma saúde que responda às necessidades dos usuários desses sistemas sem considerar os elementos sociais, culturais e econômicos, os quais influem nos meio sociais em que as ações serão desenvolvidas. Em respeito aos direitos econômicos, sociais e culturais, dentre os quais se insere o direito à saúde, estes foram desenvolvidos no Pacto Internacional de Direitos Econômicos, Sociais e Culturais. Na seara dos documentos internacionais que tratam sobre o direito à saúde, ressalta-se a importância das Conferências Internacionais. Um ponto referencial em todas as Cartas/Declarações que traduzem os resultados dos debates nessas conferências é a superação de uma concepção de saúde vinculada ao modelo biomédico e a adoção de um modelo de saúde, inclusivo, que respeite as diversidades regionais, locais e culturais, que não vislumbre a promoção da saúde somente como um processo de cura de doenças. Dentro dessa nova realidade, o fortalecimento da participação comunitária, tanto no planejamento quanto na execução e controle das ações de saúde é fundamental.

Palavras-chave: Direitos humanos; participação comunitária; direito à saúde; conferências internacionais de saúde.

Key-words: Human rights; community participation; right to health; international conferences on health. 


\section{Introdução}

Este estudo objetiva analisar como o direito à saúde e a participação comunitária em saúde tem sido tratados (direta ou indiretamente), em documentos internacionais que rezam sobre os direitos humanos de formal geral ou naqueles originários dos fóruns da Organização Mundial de Saúde (OMS).

Para este estudo, destacaremos a Declaração Universal dos Direitos Humanos (DUDH); o Pacto Internacional dos Direitos Civis e Políticos (PIDCP); o Pacto Internacional dos Direitos Econômicos, Sociais e Culturais (PIDESC); e as Conferências Internacionais de Alma-Alta, URSS (1978), Ottawa, Canadá (1986), Adelaide, Austrália (1988), Sundsvall, Suécia (1991), Bogotá, Colômbia (1992), Jacarta, Indonésia (1997), Cidade do México, México (2000) e Bangkok, Tailândia (2005).

\section{A Declaração Universal dos Direitos Humanos (DUDH), Pacto Internacional de Direitos Econômicos, Sociais e Culturais (PIDESC) e o Pacto Internacional dos Direitos Civis e Políticos (PIDCP)}

A DUDH foi proclamada em 1948 pela ONU (sendo o Brasil seu signatário desde o ato de sua aprovação e proclamação), ainda sob os efeitos das atrocidades cometidas durante a Segunda Guerra Mundial. Mesmo sem poder vinculativo, estabelece um conjunto de princípios concernentes aos denominados direitos humanos. Deve-se registrar que a declaração não trata especificamente da saúde, mas estabelece fundamentos que indiretamente interagem com o conceito de saúde da OMS.

Logo em seu preâmbulo, preceitua:

[...] o desprezo e o desrespeito pelos direitos humanos resultaram em atos bárbaros que ultrajaram a consciência da Humanidade e que o advento de um mundo em que os homens gozem de liberdade de palavra, de crença e da liberdade de viverem a salvo do temor e da necessidade foi proclamado como a mais alta aspiração do homem comum, [...] que os povos das Nações Unidas reafirmaram, na Carta, sua fé nos direitos humanos fundamentais, na dignidade e no valor da pessoa humana e na igualdade de direitos dos homens e das mulheres, e que decidiram promover o progresso social e melhores condições de vida em uma liberdade mais ampla. (DUDH, 1948)

Entende Dallari (2009) que o texto da DUDH reforça três elementos fundamentais: a) a existência da "certeza" dos direitos, ou seja, que ocorra o 
estabelecimento prévio e claro dos direitos e das obrigações, com o intuito de os sujeitos poderem usufruir desses direitos sem que haja quaisquer imposições ou condicionamentos; b) que tais direitos estejam seguros, exigindo a existência de normas que preceituem que "em qualquer circunstância" haverá o devido respeito e cumprimento dos direitos humanos/fundamentais; c) a existência concreta de possibilidade dos direitos, para que não expressem apenas uma igualdade formal e possam permitir a verdadeira fruição destes por "todos".

Para Piovesan (2008, p. 137), "a universalidade dos direitos humanos traduz a absoluta ruptura com o legado nazista, que condicionava a titularidade de direitos à pertinência à determinada raça [...]". Entretanto, destaca-se que essa universalidade deve se inserir no contexto da interculturalidade/multiculturalidade.

O texto da declaração, a partir do artigo 23 , começa a tratar dos direitos econômicos, sociais e culturais, estabelecendo no artigo 25 , I, que:

Toda pessoa tem direito a um padrão de vida capaz de assegurar a si e a sua família saúde e bem estar, inclusive alimentação, vestuário, habitação, cuidados médicos e os serviços sociais indispensáveis, e direito à segurança em caso de desemprego, doença, invalidez, viuvez, velhice ou outros casos de perda dos meios de subsistência fora de seu controle. (DUDH, 1948)

Portanto, a DUDH não dissocia a saúde dos outros condicionantes necessários para que se possa ter uma vida digna. Isto é, não se pode avaliar a existência ou não de uma saúde que responda as necessidades dos usuários desses sistemas sem considerar os elementos sociais, culturais e econômicos, os quais influem nos meio sociais em que as ações serão desenvolvidas.

Ademais, é importante também ressaltar o artigo 21, I, da DUDH (1948), que reza: "toda pessoa tem o direito de tomar parte no governo de seu país, diretamente ou por intermédio de representantes livremente escolhidos". Ora, o que se extrai desse artigo é que o texto da DUDH ampara o exercício de uma cidadania participativa ao lado da cidadania representada.

Igualmente, a Convenção Americana de Direitos Humanos (promulgada pelo Brasil por meio do Decreto № 678, de 6 de novembro de 1992) reza em seu artigo 1ㄴ, itens 1 e 2 , que:

1. Toda pessoa tem direito à saúde, compreendendo-se como saúde o gozo do mais alto nível de bem-estar físico, mental e social. 2. A fim de tornar efetivo o direito à saúde, os Estados-Partes comprometemse a reconhecer a saúde com bem público [...]. (CADH, 1969) 
Em respeito aos direitos econômicos, sociais e culturais, dentre os quais se insere o direito à saúde, estes foram desenvolvidos no Pacto Internacional de Direitos Econômicos, Sociais e Culturais (PIDESC). Este documento foi aprovado pela Assembleia Geral da ONU pela Resolução no 2.220a, de 16 de dezembro de 1966, mas somente entrou em vigor em 3 de janeiro de 1976. O Brasil somente veio a ratificá-lo em 24/01/1992 (foi aprovado pelo Decreto Legislativo oㅜ 226, de 12/12/1991, e promulgado pelo Decreto no 591, de 06/07/1992). No que diz respeito ao direito à saúde, o PIDESC (1966) dispõe no artigo 12 que:

$\S 1$. Os Estados-partes no presente Pacto reconhecem o direito de toda pessoa de desfrutar o mais elevado nível de saúde física e mental. § 2. As medidas que os Estados-partes no presente Pacto deverão adotar, com o fim de assegurar o pleno exercício desse direito, incluirão as medidas que se façam necessárias para assegurar: 1. A diminuição da mortinatalidade e da mortalidade infantil, bem como o desenvolvimento são das crianças. 2. A melhoria de todos os aspectos de higiene do trabalho e do meio ambiente. 3. A prevenção e o tratamento das doenças epidêmicas, endêmicas, profissionais e outras, bem como a luta contra essas doenças. 4. A criação de condições que assegurem a todos assistência médica e serviços médicos em caso de enfermidade.

Sobre a restrição à aplicação dos direitos sociais, nos quais se inclui a saúde, prescreve Piovesan (2008, p. 180-181):

Acredita-se que a idéia de não-acionabilidade dos direitos sociais é meramente ideológica e não científica. É uma pré-concepção que reforça a equivocada noção de uma classe de direitos (os direitos civis e políticos) merece inteiro reconhecimento e respeito, enquanto outra classe (os direitos sociais, econômicos e culturais), ao revés, não merece qualquer reconhecimento.

O PIDCP (1966) reproduz em seu artigo 25, "caput" e alínea "a", um princípio já inserido na DUDH, de que toda pessoa/cidadão tem o direito de participar das decisões políticas e dos assuntos públicos de seu país, mediante representantes ou diretamente. Outrossim, no artigo $1^{\circ}$, I, estabelece como direito de cada povo determinar livremente a sua forma de organização política, bem como a forma de estabelecer o seu desenvolvimento econômico, social e cultural. Portanto, não pode haver um modelo imposto de organização e funcionamento social, econômico e político para todos os povos, devendo-se respeitar o seu processo histórico de formação e os elementos culturais que são inerentes a cada sociedade.

Igualmente, deve-se superar a dicotomia direitos civis e políticos $\mathrm{x}$ direitos econômicos, sociais e culturais, no sentido de que somente da concretização dos 
primeiros é que se poderão exercer os outros. Nada mais absurdo e excludente, já que traz no seu bojo uma concepção de se compreender a existência de direitos como uma ação negativa frente ao Estado e que visualizam os direitos coletivos como normas programáticas, o que se concretiza como uma verdadeira negação desses direitos.

Sobre essa aparente dicotomia, expressa Piovesan (2008, p. 142):

Vale dizer, se a efetividade dos direitos econômicos, sociais e culturais, os direitos civis e políticos se reduzem a meras categorias formais, enquanto, sem a realização dos direitos civis e políticos, ou seja, sem a efetividade da liberdade entendida em seu mais amplo sentido, os direitos econômicos, sociais e culturais carecem de verdadeira significação. Não há mais como cogitar da liberdade divorciada da justiça social, como também infrutífero pensar na justiça social divorciada da liberdade. Em suma, todos os direitos humanos constituem um complexo integral, único e indivisível, no qual os diferentes direitos estão necessariamente inter-relacionados e são interdependentes entre si.

Isso fica claro no caso da saúde, que interliga totalmente com o direito à vida e o de participação política, pois a saúde é uma condição para que a vida possa ser preservada e não prescinde da participação da coletividade na sua construção.

Dallari (2003, p. 48) aponta uma característica dos documentos internacionais em direitos humanos que tratam do conceito de saúde, como este sendo:

[...] o mais amplo possível, abrangendo desde a típica face individual do direito subjetivo à assistência médica [não só médica, mas de todos os serviços de saúde e de todos os profissionais ligados ao campo saúde] em caso de doença, até a constatação da necessidade do direito do Estado ao desenvolvimento, personificada no direito a um nível adequado à manutenção da dignidade humana. Isso sem esquecer do direito à igualdade, implícito nas ações de saúde de caráter coletivo tendentes a prevenir e tratar epidemias ou endemias, por exemplo.

\section{As conferências internacionais de saúde}

Ainda na seara dos documentos internacionais que tratam sobre o direito à saúde, ressalta-se a importância das conferências internacionais. Um ponto referencial em todas as Cartas/Declarações que traduzem os resultados dos debates nessas conferências é a superação de uma concepção de saúde vinculada ao modelo biomédico e a adoção de um modelo de saúde, inclusivo, que respeite as diversidades regionais, locais e culturais, que não vislumbre a promoção da saúde somente como um processo de cura de doenças. Dentro dessa nova realidade, o 
fortalecimento da participação comunitária, tanto no planejamento quanto na execução e controle das ações de saúde é fundamental. Essa participação da coletividade deve ser incentivada, promovendo espaços de obtenção de informação e de aprendizado sobre a saúde para estes novos atores sociais. Assim, deve ser garantido que a Sociedade venha participar do processo de mediação da construção da saúde de todos.

Entre os dias 6 e 12 de setembro de 1978 ocorreu na cidade de Alma-Ata, na então União das Repúblicas Socialistas Soviéticas (URSS), a Conferência Internacional sobre Cuidados Primários de Saúde ${ }^{1}$. O texto da Declaração de AlmaAta, aprovado em 12 de setembro de 1978, teve como referência a urgência de se promover a saúde de todos os povos, mediante ação dos Estados e de todos aqueles que trabalhavam no campo da saúde. Essa Declaração constituiu-se um marco, por estabelecer princípios e metas para que se pudesse ter até o ano 2000, a nível mundial, uma saúde "aceitável" para todos os povos do mundo (Declaração de AlmaAta, 1978).

Em seu inciso I, a Declaração de Alma-Ata (1978), reforçando o conceito já estabelecido na Constituição da OMS, diz que a saúde é

[...] um direito humano fundamental, e que a consecução do mais alto nível possível de saúde é a mais importante meta social mundial, cuja realização requer a ação de muitos outros setores sociais e econômicos, além do setor saúde.

Portanto, a Declaração reforça a concepção de que ter saúde não se constitui apenas em ações, mas em um conjunto de outros fatores que envolvem elementos sociais e econômicos e que, direta ou indiretamente, influenciam o nível de saúde da população. Desse modo, na qualidade de direito, ela implica ser construída pela participação popular e comunitária, conforme preceitua o seu inciso IV que "é direito e

\footnotetext{
${ }^{1}$ Conforme o inciso VI da Declaração de Alma-Ata (1978): Os cuidados primários de saúde são cuidados essenciais de saúde baseados em métodos e tecnologias práticas, cientificamente bem fundamentadas e socialmente aceitáveis, colocadas ao alcance universal de indivíduos e famílias da comunidade, mediante sua plena participação e a um custo que a comunidade e o país possam manter em cada fase de seu desenvolvimento, no espírito de autoconfiança e automedicação. Fazem parte integrante tanto do sistema de saúde do país, do qual constituem a função central e o foco principal, quanto do desenvolvimento social e econômico global da comunidade. Representam o primeiro nível de contato dos indivíduos, da família e da comunidade com o sistema nacional de saúde, pelo qual os cuidados de saúde são levados o mais proximamente possível aos lugares onde pessoas vivem e trabalham, e constituem o primeiro elemento de um continuado processo de assistência à saúde.
} 
dever dos povos participar individual e coletivamente no planejamento e na execução de seus cuidados de saúde" (Declaração de Alma-Ata, 1978).

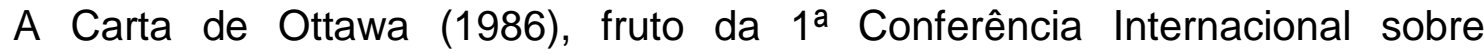
Promoção da Saúde, definiu não ser possível promovê-la sem que haja efetivamente a participação comunitária. Inicialmente, o texto da Carta define tal promoção como o "processo de capacitação da comunidade para atuar na melhoria de sua qualidade de vida e saúde, incluindo uma maior participação no controle deste processo".

Desse modo, a promoção da saúde é desenvolvida pela realização de:

[...] ações comunitárias concretas e efetivas no desenvolvimento das prioridades, na tomada de decisão, na definição de estratégias e na sua implementação, visando a melhoria das condições de saúde. 0 centro deste processo é o incremento do poder das comunidades a posse e o controle dos seus próprios esforços e destino. $O$ desenvolvimento das comunidades é feito sobre os recursos humanos e materiais nelas existentes para intensificar a auto-ajuda e o apoio social, e para desenvolver sistemas flexíveis de reforço da participação popular na direção dos assuntos de saúde. Isto requer um total e contínuo acesso à informação, às oportunidades de aprendizado para os assuntos de saúde, assim como apoio financeiro adequado. (Carta de Ottawa, 1986 - grifo nosso)

Além disso, preceituou que a concretização e a defesa da saúde não podem ficar adstritas apenas ao seu setor, mas devem envolver uma ação/participação organizada/coordenada de todas as partes envolvidas, seja o governo, os membros de outros setores sociais, as organizações não governamentais, a mídia, os setores econômicos e industriais etc. (Carta de Ottawa, 1986), ou seja, deve envolver a Sociedade e não apenas a esfera pública estatal, pois o bem coletivo saúde interessa a toda coletividade.

As demais conferências reforçaram os preceitos das Conferências de Alma-Ata (1978) e de Ottawa (1986) e destacaram a importância da participação comunitária no processo de construção da saúde, senão vejamos: 1) Declaração de Adelaide (1988): a) deve-se reforçar o papel da comunidade no processo de promoção da saúde, pois "a ação comunitária é um ponto central da promoção de políticas saudáveis"; b) além disso, dentro dos processos decisórios das políticas de saúde, deve-se inovar no estabelecimento de novas formas de participação para esses atores sociais que interagem com tal campo. 2) Declaração de Sundsvall (1991): a) capacitar a comunidade e os indivíduos a terem maior controle acerca de sua saúde e também dos seus processos de decisão; b) construir alianças que possam fortalecer a 
promoção da saúde. 3) Declaração de Santafé de Bogotá (1992), que teve por objetivo central a promoção da saúde na América Latina: a) reforçar a "capacidade da população nas tomadas de decisões que afetem a sua vida [...]". 4) Declaração de Jacarta (1997): a) dispôs que "a saúde é um direito humano fundamental e essencial para o desenvolvimento social e econômico"; b) que o processo de participação comunitária é fundamental para promover a saúde; c) a participação se torna mais eficaz e consegue ampliar o papel da sociedade nos processos de tomada de decisão em saúde, quando existe acesso à instrução e à informação sobre esta e sobre os fatores que se inter-relacionam com ela, e que implicam na qualidade dos serviços de saúde prestados. 5) Declaração do México (2000): a) também destacou a importância da participação da comunidade na promoção da saúde. 6) Carta de Bangkok (2005): a) "advogar pela saúde com base nos direitos humanos e na solidariedade"; b) o fortalecimento da sociedade civil no processo de promoção da saúde.

\section{Conclusão}

A participação comunitária em saúde constitui instrumento necessário para a concretização do direito à saúde, conforme é declarado nos documentos internacionais sobre direitos humanos.

As declarações e cartas das conferências internacionais de saúde, sinergicamente exigiram - como condição para existir a promoção da saúde - que haja a participação concreta da sociedade no planejamento e na realização de tais ações.

Nesse sentido, a Declaração de Jacarta (1997 - grifo no original) consegue sintetizar paradigmaticamente essa concepção de direito à saúde vinculada a participação da sociedade em sua elaboração e concretização, quando prescreveu que "a promoção da saúde efetua-se pelo e com o povo, e não sobre e para o povo".

\section{Referências}

CADH. Convenção Americana de Direitos Humanos, de 1969. Disponível em: <http://www.planalto.gov.br/ccivil_03/decreto/1990-1994/anexo/andec678-92.pdf>.

Acesso em: 28.01.2010.

CARTA DE BANGKOK. 6ª Conferência Internacional de Promoção da Saúde, 2005. Disponível em: $<$ http://www.bvsde.ops-oms.org/ bvsdeps/fulltext/cartabangkokpor.pdf>. Acesso em: 20 fev. 2013. 
CARTA DE OTTAWA. 1ª Conferência Internacional sobre Promoção da Saúde, 1988. Disponível em: <http://cmdss2011.org/site/ wp-content/uploads/2011/07/Ottawa.pdf>. Acesso em: 20 fev. 2013.

DALLARI, Sueli Gandolfi. Direito sanitário. In: ARANHA, Márcio lorio (Org.). Direito sanitário e saúde pública. v. 1: Coletânea de Textos. p. 39-64. Brasília: Ministério da Saúde, 2003.

DALLARI, Dalmo de Abreu. Elementos de teoria geral do Estado. 28 ed. São Paulo: Saraiva, 2009.

DECLARAÇÃO DE ADELAIDE. 2ª Conferência Internacional de Promoção da Saúde, 1988. Disponível em: <http://www.saudepublica. web.pt/05promocaosaude/Dec_Adelaide.htm>. Acesso em: 20 fev. 2013.

DECLARAÇÃO DE ALMA-ATA. Conferência Internacional sobre Cuidados Primários em Saúde, $1978 . \quad$ Disponível em: <www.dgidc. minedu.pt/educacaosaude/data/.../1_alma_ata_nesase. pdf>. Acesso em: 20 fev. 2013.

DECLARAÇÃO DE JACARTA. 4ª Conferência Internacional de Saúde, 1997. Disponível em: $<$ http://www.who.int/healthpromotion/con ferences/previous/jakarta/en/hpr_jakarta_declaration_portuguese.pdf $>$. Acesso em: 20 fev. 2013. $\begin{array}{llll}\text { DECLARAÇÃO DE SANTAFÉ DE BOGOTÁ. Conferência Internacional de Promoção } \\ \text { da Saúde, } & 1992 . & \text { Disponível } & \text { em: }\end{array}$ www.saude.al.gov.br/print/declaraodesantafdebogot-27-12-2007>. Acesso em: 20 fev. 2013.

DECLARAÇÃO DE SUNDSVALL. 3aㅡ Conferência Internacional de Promoção da Saúde, $1991 . \quad$ Disponível em: <http://www.dgidc.minedu.pt/educacaosaude/data/.../4_sundsvall_nesase.pdf>. Acesso em: 20 fev. 2013.

DECLARAÇÃO DO MÉXICO. 5a Conferência Internacional sobre Promoção da Saúde, 2000. Disponível em: <www.dgidc.min-edu.pt/ educacaosaude/data/.../6_mexico_nesase.pdf>. Acesso em: 20 fev. 2013.

DUDH. Declaração Universal dos Direitos Humanos. Adotada e proclamada pela Resolução 217A (III) da Assembleia Geral das Nações Unidas em 10 de dezembro de 1948. Disponível em: <http://portal.mj. gov.br/sedh/ct/legis_intern/ddh_bib_inter_universal.htm>. Acesso em: 20 fev. 2013.

PIDCP. Pacto Internacional dos Direitos Civis e Políticos, aprovado pela Assembleia Geral da ONU através da Resolução n 2.220a, de 06 de dezembro de 1966. Disponível em: <http://www.oas.org/dil/port/ 1966\%20Pacto\%20Internacional\%20sobre\%20Direitos\%20Civis\%20e\%20Pol\%C3\% ADticos.pdf>. Acesso em: 20 fev. 2013.

PIDESC. Pacto Internacional de Direitos Econômicos, Sociais e Culturais, aprovado pela Assembleia Geral da ONU através da Resolução ํㅡㄴ 2.220a, de 16 de dezembro de $1966 . \quad$ Disponível em: <http://www.oas.org/dil/port/1966\%20Pacto\%20Internacional\%20sobre\%20os\%20Dire itos\%20Econ\%C3\%B3micos,\%20Sociais\%20e\%20Cultu rais.pdf>. Acesso em: 20 fev. 2013. 
Anais dos III Congresso Iberoamericano de Direito Sanitário / II Congresso Brasileiro de Direito Sanitário

PIOVESAN, Flávia. Direitos humanos e o direito constitucional internacional. 9. ed. São Paulo: Saraiva, 2008. 